\section{Social disruption of discriminated avoidance behavior}

\author{
RANDALL K. FLORY and KATHARINE FRENCH \\ Hollins College, Hollins College, Va. 24020
}

Two groups of rats were trained to respond on a discriminated avoidance schedule. For those animals that were initially trained together, escape rather than avoidance behavior occurred. Sexual mounting behavior and attack behavior were also observed. Those animals that were trained individually on the avoidance schedule seldom attacked when later paired with an unrestrained naive animal. Furthermore, the relative position of the naive animal in the chamber appeared to determine whether an avoidance or an escape response occurred. Disruption of discriminated avoidance responding appeared to be due not only to competing attack behavior, but also to the presence and position of the other animal in the chamber.

Aggressive behavior can be elicited between paired animals when an aversive stimulus such as electric shock is presented (see general review by Ulrich, Hutchinson, \& Azrin, 1965). Several investigators have studied the relationship between pain-elicited aggression and conditioned escape or avoidance behavior. Ulrich \& Craine (1964) reported a significant reduction in established avoidance responding upon the presentation of a naive $S$. Ulrich (1967) found that the cooperative escape behavior of rats separated by a clear Plexiglas partition was to investigate the disruption of discriminated avoidance behavior in a social situation and to investigate further those behaviors such as aggression that come to accompany and/or compete with the avoidance behavior.

\section{SUBJECTS}

Six female and four male naive Sprague-Dawley rats were used. Each $S, 120-130$ days of age at the beginning of the study, was housed individually in a temperaturecontrolled and constantly illuminated room and was maintained on free food and water.

\section{APPARATUS}

A Lehigh Valley Model 1417 test chamber was used. The inner working space measured $26.5 \times 30.5 \times 24.0 \mathrm{~cm}$. A response lever requiring $20 \mathrm{~g}$ of force for operation was located on one wall. The floor consisted of parallel steel bars through which shock was delivered by a Lehigh Valley Model 1531 constant-current shock generator equipped with a shock scrambler. A houselight located on the ceiling of the chamber provided sufficient illumination for observation of the animals' behavior through a one-way window. Conventional electromagnetic equipment was used to program events, while digital counters and a cumulative recorder were used to record behavior.

$$
\text { PROCEDURE }
$$

A discriminated avoidance schedule was used. Two discriminative stimuli, a pulsed light and tone, were simultaneously presented for $5 \mathrm{sec}$ prior to the onset of shock. A leverpress made any time after the onset of the stimuli terminated the light and tone and postponed for 25 sec the onset of the next warning period. If a response was not emitted during the 5 -sec warning period, a 2-mA grid shock with duration and shock-shock interval of $1.5 \mathrm{sec}$ occurred in the presence of light and tone until a response terminated shock and stimuli and postponed the onset of the warning stimuli for $25 \mathrm{sec}$.

The Ss were divided randomly into two groups. One group consisted of two males and two females. One $S$ of each sex was trained individually on the avoidance schedule until $80 \%$ or more of potential shock periods were avoided for at least eight consecutive sessions. Once stable avoidance behavior was established, each of the Ss was paired with a naive unrestrained rat of the same sex and further exposed to the dscriminated avoidance schedule. A second group of rats consisted of two males and four females. The Ss in this group were paired according to se $x$ and exposed to the discriminated avoidance schedule for 15 sessions. Sessions, which were 
conducted 7 days per week, consisted of the presentation of 100 warning periods.

An attack was defined as a striking movement by either one or both rats while standing on their hindlegs in the stereotyped fighting position (Ulrich \& Azrin, 1962). The accurate recording of attack episodes was confirmed by reliability checks run by having two different Os simultaneously record the fighting behavior.

\section{RESULTS}

Figure 1 shows avoidance behavior as a function of sessions for both groups of Ss. Established avoidance responding for both single Ss 1 and 2 was disrupted when a naive unrestrained $S$ was introduced on Session 21. Avoidance responding decreased from $91 \%$ for both $\mathrm{S} 1$ and S 2 to $52 \%$ for the female $S 1$ and $31 \%$ for the male S 2 when a second rat was placed in the chamber. For S 2, the level of avoidance behavior established just prior to pairing was reestablished on the fourth session following the introduction of the second $\mathrm{S}$. For $\mathrm{S} 1$, however, the addition of a second rat resulted in a level of avoidance that remained consistently below that established by $\mathrm{S} 1$ alone.

Each of the three pairs of naive Ss that was exposed to the discriminated avoidance schedule for 15 sessions exhibited little or no avoidance behavior. The greatest number of session avoidance responses for any of the three pairs was seven. Observation of these animals revealed that shock termination rather. than shock postponement was the most prevalent behavior.
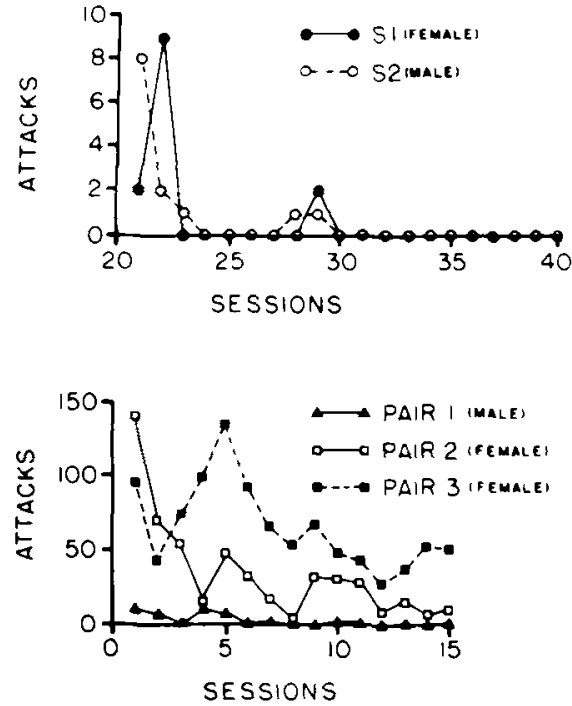

Fig. 2. Upper portion shows number of attacks per session for rats $S 1$ and $S 2$ initially trained alone and then paired with naive Ss on Sessions 21-40. Lower portion shows number of attacks per session for Ss exposed to the avoidance schedule in pairs on Sessions 1-15.

When $S 1$ and S 2 were paired with naive Ss, relatively little attack behavior occurred, as is shown in the upper portion of Fig. 2. The lower portion of Fig. 2 shows that for the three pairs of naive Ss there was a general decrease in session attacks as a function of continued exposure to the discriminated avoidance schedule. Although the male pair seldom attacked, observation of the two

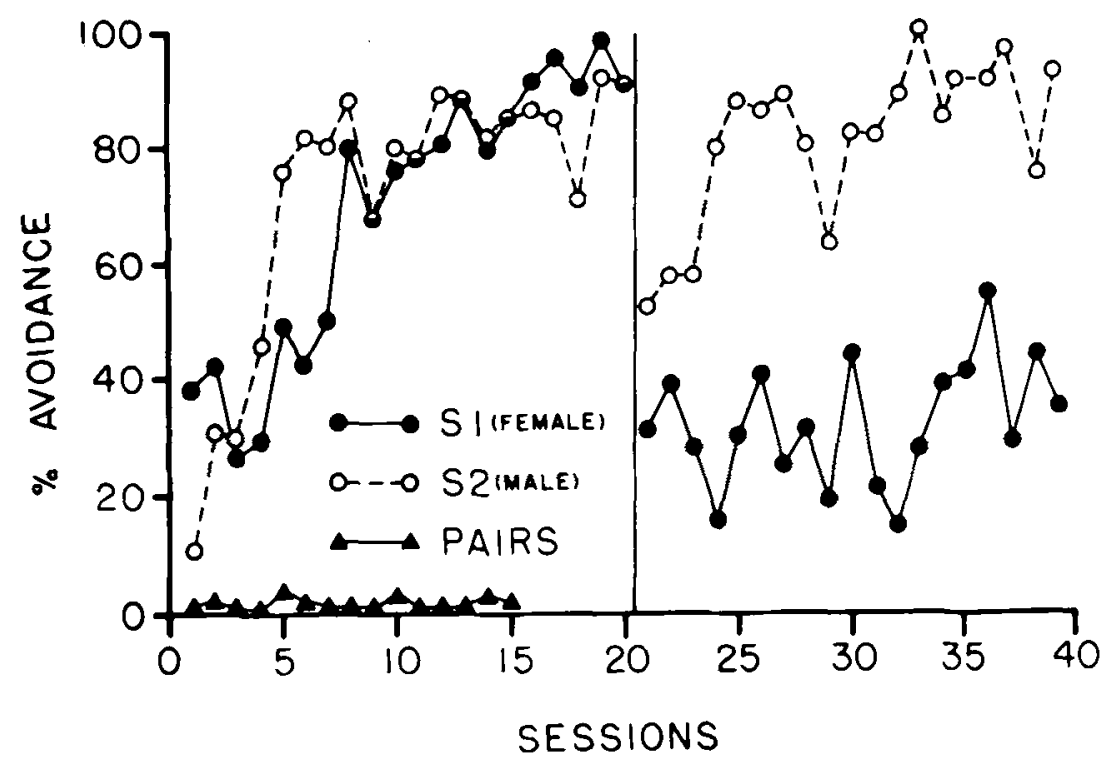

Fig. 1. Percent of total session shock periods avoided as a function of sessions for six rats initially paired and for two rats initially trained alone, and then each paired with a naive rat on Session 21 . Individual data points are plotted for $S 1$ and S 2, whereas median data points are plotted for the initially paired Ss. female pairs revealed that they frequently attacked shortly after shock presentation. Furthermore, behavior resembling that of sexual mounting was consistently observed for the two female pairs of Ss. For Pair No. 3 , the avoider $S$ typically attacked when the other rat mounted, whereas for Pair No. 2, few attacks were observed when the avoider mounted the second $S$.

\section{DISCUSSION}

The results of the present experiment indicate that both acquisition and maintenance of discriminated avoidance behavior are greatly influenced by the presence and physical position of a second organism in the experimental situation.

In a previous study, exposure of pairs of rats to a Sidman (1953) avoidance schedule resulted in the acquisition of avoidance responding (Ulrich, Stachnik, Brierton, \& Mabry, 1965). This was not the case when pairs of rats were exposed to a discriminated avoidance schedule in the present study, Attack behavior, because it seldom occurred, did not appear to compete with the opportunity of paired Ss to acquire the avoidance behavior. Rather, it appeared that the mere presence of another animal in the chamber prevented the normal acquisition of avoidance responding. The disruption of previously established avoidance behavior of those Ss that were later paired with naive rats also did not appear to be the result of competing attack behavior since only 11 attacks were observed for each pair over the first three sessions in the social situation. The difference observed between the two individually trained animals with respect to the reestablishment of avoidance responding following pairing with naive Ss could possibly have been due to a sex difference. Further systematic study is needed to investigate this possibility.

\section{REFERENCES}

SIDMAN, M. Avoidance conditioning with brief shock and no exteroceptive warning signal. Science, 1953, 118, 157-158.

ULRICH, R. E. Interaction between reflexive fighting and cooperative escape. Journal of the Experimental Analysis of Behavior, 1967, 10, 311-317.

ULRICH, R. E.. \& AZRIN, N. H. Reflexive fighting in response to aversive stimulation. Journal of the Experimental Analysis of Behavior, $1962,5,511.520$.

ULRICH, R. E.. \& CRAINE, W. H Behavior: Persistence of shock-induced aggression. Science, 1964, 143,971-973.

ULRICH, R. E, HUTCHINSON, R. R., \& AZRIN, N. H. Pain-elicited aggression. Psychological Record, 1965, 15, $111-126$.

ULRICH, R. E., STACHNIK, T. J.. BRIERTON, G. R., \& MABRY. J. H. Fighting and avoidance in response to aversive stimulation. Behaviour, 1966,46 , 124-129. 